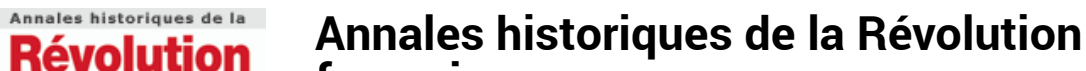

française française

324 | avril-juin 2001

Louis Charles Antoine Desaix. Officier du roi, Général de la République

\section{Un juif rebelle dans la Révolution, La vie de Zalkind Hourwitz (1751-1812).}

\section{Pierre Serna}

\section{(2) OpenEdition \\ Journals}

Édition électronique

URL : https://journals.openedition.org/ahrf/1123

DOI : $10.4000 /$ ahrf. 1123

ISSN : 1952-403X

Éditeur :

Armand Colin, Société des études robespierristes

Édition imprimée

Date de publication : 1 juin 2001

Pagination : 211-213

ISSN : 0003-4436

Référence électronique

Pierre Serna, « Un juif rebelle dans la Révolution, La vie de Zalkind Hourwitz (1751-1812). », Annales historiques de la Révolution française [En ligne], 324 | avril-juin 2001, mis en ligne le 21 avril 2004 consulté le 24 avril 2022. URL : http://journals.openedition.org/ahrf/1123 ; DOI : https://doi.org/ 10.4000/ahrf.1123

Ce document a été généré automatiquement le 24 avril 2022.

Tous droits réservés 


\title{
Un juif rebelle dans la Révolution, La vie de Zalkind Hourwitz (1751-1812).
}

\author{
Pierre Serna
}

\section{RÉFÉRENCE}

Frances Malino, Un juif rebelle dans la Révolution, La vie de Zalkind Hourwitz (1751-1812),

Paris, Berg International éditeurs, 2000, 243 p.

1 Plutôt que de présenter un débat d'idées sur la question de l'émancipation réelle ou non des juifs durant la Révolution française, l'auteur, Frances Malino, illustre son propos en étudiant le parcours d'un homme, Zalkind Hourwitz, juif polonais, dont la fidélité aux idéaux de 1789 ne s'est jamais démentie, et qui, sous tous les régimes, n'a eu de cesse que de détendre la dignité de sa communauté par la conquête de ses droits civils. Né en 1751, décédé en 1812, le personnage, immigrant, étranger, puis finalement citoyen français, juif et révolutionnaire, se présente comme une figure atypique dans la galerie de portraits laissés par la Révolution.

2 Résidant en France depuis 1774, Hourwitz, modeste colporteur d'habits à Paris, décide, en 1787, de participer au concours de l'Académie des arts et des sciences de Metz, qu'inspire Roederer: «Est-il des moyens de rendre les juifs plus heureux et plus utiles en France?» L'argumentaire d'Hourwitz ne sert, dans un premier temps, qu'à démontrer les limites humiliantes de la formule. En un mot, pour rendre utiles et heureux les juifs de France, il faut en faire d'abord des sujets-citoyens comme tous les autres. Il ne s'agit pas de les régénérer eux en particulier, mais d'abolir l'injustice religieuse politique, sociale, en un mot transformer la société chrétienne et monarchique qui les maintient dans cette infériorité infamante. Seul juif à concourir, il remporte le prix avec l'abbé Grégoire et l'avocat protestant Thiéry, dont il partage de nombreuses idées sans toutefois reconnaître comme eux, la nécessité pour les juifs de 
se corriger par l'inclusion dans la nation ou par leur conversion, afin de ne plus être considérés comme étrangers.

3 En 1789, Hourwitz reprend son mémoire et le fait éditer sous le titre d'Apologie des juifs. Expliquer sans relâche les particularismes des juifs, exiger pour eux l'égalité, mais aussi, fustiger les marques d'obscurantisme de ses coreligionnaires, devient désormais l'objectif de toutes les interventions publiques d'Hourwitz.

4 Le troisième chapitre, «La voix d'un révolutionnaire juif», est peut être le plus réussi, car c'est là que s'affirme la vocation d'Hourwitz, celle «d'un juif», comme il l'écrit, luimême, le 7 novembre 1789, dans le Mercure de France, «[qui] s'est chargé de défendre la nation et de réclamer pour elle, ces droits imprescriptibles et communs à tous les hommes».

Dès le printemps 1789, Hourwitz formule l'alternative pour la communauté juive: ou bien des améliorations matérielles, limitées par une infériorité politique, ou bien une franche égalité civique, payée par l'abolition de l'autonomie juridique des communautés. Il ne faut pas hésiter!

6 L'égalité entre tous les hommes, proclamée le 26 août dans la Déclaration des Droits, est loin de se traduire dans les faits pour la communauté juive qui doit encore patienter... Il fallut attendre le décret du 27 septembre 1791, devenu loi le 13 novembre, pour que les juifs puissent désormais, accéder à la citoyenneté active.

7 Dès le début de la Révolution, l'enthousiaste Hourwitz s'est engagé dans la garde nationale et participe, grâce à Gorsas, dans le Courrier de Versailles, à Paris, à l'aventure d'un journalisme politique naissant. Il est proche des personnalités du Cercle social, véritable laboratoire des idées les plus radicales.

Durant la crise politique de 1793, Hourwitz demeure à Paris, proche des Girondins, solidaire de la guerre décrétée contre les ennemis de la France. Toujours lié à Gorsas élu député à la Convention, il prête spontanément serment après la journée du 10 août. C'est naturellement qu'il se rallie à ses amis girondins au moment du procès du roi, optant pour l'appel au peuple et une détention du monarque jusqu'à la paix. Hourwitz ne reprend courageusement la parole que le 16 avril 1794, pour protester contre le décret du Comité de salut public interdisant aux étrangers, dont le pays était en guerre contre la France, de séjourner dans Paris ou dans les ports.

Il participe de nouveau au débat politique à la fin du Directoire: comment traduire l'héritage de la Révolution dans les faits, afin de stabiliser la République, et comment faire accepter celle-ci du plus grand nombre? Le souci de répondre à ces questions pensées par les idéologues est également partagé par un homme comme Hourwitz, resté proche de Grégoire et de Valentin Haüy et percevant trop aisément la fragilité du statut concédé aux juifs.

10 Les dernières années sont placées sous le signe de la surdité... L'échec politique de la Révolution, l'aspect policier du régime impérial, le renoncement à la reconnaissance pleine et entière de la citoyenneté juive dans le statut imposé par Napoléon ne peuvent convenir à Hourwitz qui, paradoxalement, par la Constitution de l'an VIII, est devenu citoyen français. Un dernier point sur les décrets échelonnés entre mai 1806 et mars 1808 , autant de textes humiliants pour les juifs soumis à des restrictions militaires, économiques et géographiques, concluent le livre de F. Malino.

11 Fort intéressante la conclusion situe Hourwitz face au jugement de ses historiens et montre comment l'appréciation du juif révolutionnaire a pu évoluer, de sa généreuse 
réhabilitation pendant l'affaire Dreyfus où il fait alors figure de premier juif, «fou de la République», aux sérieuses réserves qui donnent de lui, durant l'entre-deux guerres, l'image d'un juif émigré venant défier les autorités juives constituées...

Les références nombreuses à la presse révolutionnaire et à l'œuvre originale sont bienvenues. En revanche, les références bibliographiques sont pour le moins étonnantes: des ouvrages essentiels et récents, sur Cloots, sur les étrangers et la Révolution, sur les idéologues, entre autres, ne sont pas même mentionnés. Ainsi, la compréhension du contexte dans lequel Hourwitz prend la plume ou la parole demeure difficile pour qui ne maîtrise pas la trame chronologique de la Révolution. Ces remarques ne retirent rien à la fermeté de la conclusion de l'historienne: la Révolution est bien l'événement politique qui a permis de penser une intégration républicaine de la communauté juive dans la vie politique française.

Finalement. l'ouvrage pose deux problèmes, politique et historique, passionnants... Le premier est celui des contradictions constitutives d'un individu et de ses rapports avec sa communauté. La position d'Hourwitz, solidaire et solitaire, met en valeur toute la complexité du contrat politique pensé par la Révolution, contrat avançant la régénération de tous les citoyens (et pas seulement des juifs) et leur union sans distinction, comme conditions exclusives de la réussite du projet politique. Cette difficulté à reconnaître l'altérité de chacun, à la base du tissu social, explique en partie, la radicalisation de 1793, le refus de penser les juifs comme une communauté à part et, en retour, la prudence, voire les silences de la communauté juive devant l'événement révolutionnaire. Ainsi s'éclaire, en revanche, la cohérence des choix politiques d'Hourwitz, en faveur d'une république girondine soucieuse de la liberté de l'individu et de son expression libre.

Mais surtout, le livre a le mérite de faire comprendre, à partir de la vie d'un seul individu, combien l'expression "communauté juive» risque d'être trompeuse. Les traits de génie, les maladresses, les colères, les explications d'Hourwitz, servent finalement à montrer combien les juifs du Roi, les juifs en Révolution, les juifs sous l'Empire, les juifs de Bordeaux, les juifs de l'Est, sont différents entre eux et parfois même opposés, en soutenant des positions qui, d'un point de vue politique, social et économique, sont loin d'être communes. Et même si les autorités et institutions, dans leur ensemble, tentent d'imposer, de la "communauté juive» une représentation globale et déformée la réalité, objective et obstinée, ne cesse de mettre en évidence, jusqu'au début du xixe siècle, un groupe de personnes divisées. L'uniformisation napoléonienne ne fera que renforcer la perception trompeuse de cette communauté. Mais, n'est-ce pas toute la société française qui était mise au pas à cette époque? 